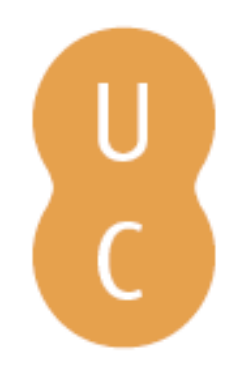

\title{
nombalina
}

\section{'Rei das Quatro Regiões': Sargão de Akkad e o modelo imperial na Mesopotâmia}

Autor(es): $\quad$ Monte, Marcel L. Paiva do

Publicado por: Imprensa da Universidade de Coimbra

URL

persistente: URI:http://hdl.handle.net/10316.2/45214

DOI: $\quad$ DOl:https://doi.org/10.14195/978-989-26-1626-1_5

Accessed : $\quad$ 26-Apr-2023 12:36:35

A navegação consulta e descarregamento dos títulos inseridos nas Bibliotecas Digitais UC Digitalis, UC Pombalina e UC Impactum, pressupõem a aceitação plena e sem reservas dos Termos e Condições de Uso destas Bibliotecas Digitais, disponíveis em https://digitalis.uc.pt/pt-pt/termos.

Conforme exposto nos referidos Termos e Condições de Uso, o descarregamento de títulos de acesso restrito requer uma licença válida de autorização devendo o utilizador aceder ao(s) documento(s) a partir de um endereço de IP da instituição detentora da supramencionada licença.

Ao utilizador é apenas permitido o descarregamento para uso pessoal, pelo que o emprego do(s) título(s) descarregado(s) para outro fim, designadamente comercial, carece de autorização do respetivo autor ou editor da obra.

Na medida em que todas as obras da UC Digitalis se encontram protegidas pelo Código do Direito de Autor e Direitos Conexos e demais legislação aplicável, toda a cópia, parcial ou total, deste documento, nos casos em que é legalmente admitida, deverá conter ou fazer-se acompanhar por este aviso. 


\section{Arqueologias de Império}

\section{Delfim Leão, José Augusto Ramos, Nuno Simões Rodrigues (coords.)}

IMPRENSA DA UNIVERSIDADE DE COIMBRA 


\title{
'Rei das Quatro Regiões': \\ SARgão de AKKad E O MODElo IMPERIAL NA Mesopotâmia ${ }^{1}$ ('King of the Four Quarters': Sargon of Akkad and the imperial model in Mesopotamia)
}

\author{
Marcel L. Paiva do Monte \\ (marcelpetroski@gmail.com; ORCID: 0000-0002-2811-3459) \\ CHAM - Centro de Humanidades, NOVA FCSH/UAc
}

\begin{abstract}
Resumo - É habitual ser atribuído à dinastia de Akkad (ca. 2334-2154 a.C.) o estatuto de «primeiro dos impérios». De facto, apesar de o domínio alargado que exerceu sobre o Próximo Oriente revelar uma continuidade com realidades anteriores, a sua vigência deu origem a uma nova tradição que estruturou a cultura política mesopotâmica. Akkad tornou-se o paradigma de um horizonte de poder universal e o seu primeiro rei, Sargão (ca. 2334-2279 a.C.), um modelo de realeza emulado muitas das entidades políticas que surgiram posteriormente na Mesopotâmia. É a esta dimensão cultural da figura de Sargão de Akkad, considerada num tempo longo, que este trabalho dará relevo. Por esse motivo, será colocado em segundo plano o contexto histórico em que decorreu o seu reinado, devido à relevância do papel de Akkad nas tradições interculturais e milenares acerca do seu império.
\end{abstract}

Palavras-Chave: Sargão de Akkad; Império; Próximo Oriente Antigo; Cultura política.

AbstraCt - It is common to attribute to the Dynasty of Akkad (ca. 2334-2154 BCE) the status of «first empire». In fact, although its widespread rule across the Ancient Near East reveals a continuity with earlier realities, it gave origin to a new tradition that structured Mesopotamian political culture and tradition in centuries to come. Akkad not only became a paradigm for universal rule, but its first king and founder, Sargon (ca. 2334-2279 BCE), was turned into a model of kingship frequently emulated in many political entities that emerged afterwards in Mesopotamia. This work will focus thus on the long-term cultural dimension of the figure of Sargon of Akkad. For that reason, and because of the millennial and intercultural traditions about the «empire» of Akkad, the proper historical context of Sargon's reign will only serve as a secondary background.

Keywords: Sargon of Akkad; Empire; Ancient Near East; Political Culture.

\footnotetext{
${ }^{1}$ Abreviaturas usadas: CAH I/2 - The Cambridge Ancient History. Vol. 1, Parte 2; RIMA 1 - The Royal Inscriptions of Mesopotamia. Assyrian Periods. Vol. 1; KUB - Keilschrifturkunden aus Boghazköi; LAPO 3 - Inscriptions royales Sumériennes et akkadiennes (Littératures Anciennes du Proche-Orient 3); MDP XI - Mémoires de la Délégation en Perse, XI: Textes Élamites-Anzanites; UET I - Ur Excavations Texts, I: Royal Inscriptions.
} 


\section{As FONTES.}

Poucos monumentos produzidos no tempo de Sargão sobreviveram até aos nossos dias. Uma única estela, fragmentada, contém a sua representação, com o nome inscrito diante da sua figura barbada ${ }^{2}$. Quanto a fontes escritas primárias, pouco mais que algumas inscrições em objetos votivos dedicados por Enheduanna, sua filha, podem ser enumeradas ${ }^{3}$. Porém, existem várias cópias de inscrições reais, efetuadas em períodos posteriores, que se consideram ter sido produzidas no seu tempo. É o caso de alguns documentos babilónicos do II milénio a.C. (período paleo-babilónico) depositados no templo de Enlil em Nippur, o Ekur ${ }^{4}$ O facto de a capital por ele fundada, a cidade de Akkad (ou Agade), não ter sido ainda encontrada pela Arqueologia, impede-nos também de aceder a arquivos e monumentos que poderiam aí existir ${ }^{5}$.

Além destas cópias de inscrições originais, a grande maioria dos textos relacionados com o primeiro rei de Akkad forma o corpus de uma tradição literária que reflete, com fiabilidade discutível, o contexto histórico da formação do seu «império». Essas referências textuais são, antes de mais, uma construção literária e ideológica desenvolvida em torno de Sargão, ao longo da Antiguidade, que o transformaram numa personagem cujas origens e ação adquirem contornos quase míticos.

Por esse motivo, a maior parte destes textos pode ser considerada como sendo mais relevante para o estudo das intenções dos seus autores e das conceções vigentes acerca do poder de Akkad ao longo da Antiguidade, no tempo em que foram produzidos, do que para o estudo do tempo a que se reportam ${ }^{6}$. A sua utilidade é, por isso, maior para o estudo das maneiras como tais conceções, das épocas em que esses textos foram redigidos, influenciaram o desenvolvimento de uma cultura política tradicional na Mesopotâmia.

A tradição acerca do primeiro rei de Akkad foi transmitida através de vários géneros textuais, desde a epopeia até ao género chamado pseudo-autobiográfi$\mathrm{Co}^{7}$. Por outro lado, podem ser também referidas listas de reis ${ }^{8}$ e compilações

${ }^{2}$ Louvre, Département des Antiquités Orientales, Sb1. Consultar Amiet 1976, 9-17 e Nigro 1998, 85-102.

${ }^{3}$ Enheduanna foi nomeada por Sargão como sacerdotisa do templo de Nanna/Su'en em Ur. UET 1, 23; 271; LAPO 3, IIA1c-d; Amiet 1976, 15, fig. 10.

${ }^{4}$ Exemplos em LAPO 3, IIA1a-b.

${ }^{5}$ O que é notado por Mario Liverani (Liverani 1993a, 6). Sobre as possíveis localizações da cidade de Akkad, ver Wall-Romana 1990.

${ }^{6}$ Cf. Liverani 1993b, 41-67; Van de Mieroop 1999, 328.

${ }^{7}$ Westenholz 1997, 33-49, textos 1 e 2. Westenholz integra, todavia, este género no plano mais geral da «literatura-narû (Westenholz 1983, 327, nota 7).

${ }^{8}$ A Lista de Reis Suméria: Jacobsen 1934; Rowton 1960, 156-62; Michalowski 1983, 237 48. 
de signos divinatórios que, em particular, mostram como o modelo de poder corporizado por Sargão foi considerado como um repositório de precedentes úteis para orientar as ações dos soberanos mesopotâmicos9.

Um exemplo da influência que a memória acerca de Sargão de Akkad exerceu, enquanto fonte ancestral de legitimação do poder, pode ser observado numa inscrição de Samsî-Addu I (ca. 1814-1775 a.C.), soberano da região que seria, mais tarde, a Assíria ${ }^{10}$. Este rei afirma ter restaurado uma parte do templo Emašmaš de Nínive, dedicado a Ištar, e que havia sido fundado por Maništušu, rei de Akkad e um dos sucessores de Sargão. Samsî-Addu reclama o mérito de ter restaurado o templo, que se encontrava delapidado,

«... e que «nenhum dos reis que me precederam reconstruiu, desde a queda de Akkad até à minha soberania.... ${ }^{11}$

Em outro extremo temporal, a continuidade da feição venerável do fundador de Akkad como elemento de uma cultura tradicional pode ser demonstrada por um documento bastante tardio que narra a história de Nabónides, último monarca da Babilónia antes da conquista aqueménida em 539 a.C. Este texto conta como Nabónides encontrou no Ebabbar, o templo de Šamaš na cidade de Sippar, várias inscrições de Narām-Sîn e uma estátua danificada onde estaria representado o próprio Sargão de $\mathrm{Akkad}^{12}$. Nabónides ordenou que a imagem fosse reparada e que lhe fossem prestadas as devidas homenagens:

«Ele viu nesse recinto sagrado uma estátua de Sargão, pai de Narām-Sîn: metade da sua cabeça desaparecera e estava tão deteriorada que a sua face estava irreconhecível. Dada a reverência [de Nabónides] pelos deuses e o seu respeito pela realeza, convocou artesãos, restaurou a cabeça dessa estátua e recolocou-lhe uma face. Ele não alterou a sua localização, mas colocou-a no Ebabbar e consagrou-lhe oblações.» $»^{13}$

Várias são as versões neoassírias e neobabilónicas de epopeias e crónicas que nos informam acerca das tradições relacionadas com Sargão. Este corpus textual, que é secundário, mas vasto e diversificado ${ }^{14}$, inclui redações em

\footnotetext{
${ }^{9}$ Cf. exemplos e bibliografia em Goetze 1947, 253-65 (sobre Sargão, 254-57). Ver também, acerca dos signos divinatórios em contexto de hepatoscopia, Liverani 1988, 256-62.

${ }^{10}$ Conhecido como reino da «Alta Mesopotâmia», com capital em Šubat-Enlil.

${ }^{11}$ RIMA 1, A.0.39.2, i 14-22.

${ }^{12}$ J.-J. Glassner (Glassner 2004, 312) indica que este documento deverá ter sido redigido já no período selêucida ou mesmo na época dos Partos (sécs. IV-III a.C.)

${ }^{13}$ RIMA 1, A.0.39.2, i 14-22.

${ }^{14}$ Para uma listagem do corpus de fontes documentais primárias e secundárias acerca de Sargão, consultar Westenholz 1997, 3-5.
} 
Sumério, Acádico ${ }^{15}$, Hitita e Hurrita ${ }^{16}$, demonstrando assim que a grande amplitude da transmissão das histórias e tradições acerca de Sargão não se limitou à Mesopotâmia e que persistiu muito além do período paleo-babilónico.

Seguindo uma opinião corrente, pode afirmar-se que a transmissão das histórias acerca de Sargão e, por conseguinte, do modelo de realeza que este configurava, se efetuara não somente por via textual, entre as elites cultas e poderosas de templos e palácios ${ }^{17}$, mas também através da oralidade, integrando o que pode ser considerado como o folclore popular mesopotâmico ${ }^{18}$.

\section{AS ORIGENS E A ASCENSÃo.}

As origens do fundador de Akkad são envoltas em mistério. A versão neoassíria do texto pseudo-autobiográfico conhecido como a Lenda de Sargão diz-nos que este terá nascido numa localidade chamada Azupirānu, situada algures nas margens do Eufrates ${ }^{19}$. Não conheceu o pai $^{20}$, mas afirma que o irmão do seu pai vivia «nas montanhas». Quanto à sua mãe, ao que consta, era uma sacerdotisa (entum) que, por alguma razão obscura, terá lançado o filho à corrente do rio dentro de um cesto impermeabilizado com betume. Vogando nas águas do Eufrates, o bebé foi recolhido por um «jardineiro» ou «carregador de água» chamado Aqqi. Este terá adotado a criança e ter-lhe-á ensinado o seu ofício. Deste modo, quando o menino cresceu, seguiu a profissão do pai adotivo ${ }^{21}$.

A partir deste ponto, é a versão mais antiga desta história, em língua suméria ${ }^{22}$, que oferece outras informações. Através dela, ficamos a saber que sobre Sargão terá recaído o olhar favorável da deusa Inanna, o que lhe terá permitido alcançar um alto posto oficial como «copeiro» (MÜŠ.KA.UL), na corte do rei de Kiš, Ur-Zababa.

Entretanto, revela-nos a história que Sargão terá tido um sonho com carácter profético, segundo o qual a deusa Inanna causava a morte a Ur-Zababa,

${ }^{15}$ No grande corpus textual de Amarna, no Egito, está incluída uma versão em língua acádica da epopeia O Rei da Batalha, o šar tamharim (Westenholz 1997, 102-33, texto 9B).

${ }^{16}$ Sobre os textos hititas sobre os reis de Akkad, podemos referir os trabalhos de $\mathrm{H}$. Güterbock (Güterbock 1934, 1938 e 1969). Referências em textos hurritas relacionados com Sargão: KUB XXVII, 38 KUB XXXI, 3 apud Westenholz 1997, 11-13; Speiser 1952, 101.

${ }_{17}$ Oppenheim 1964, capítulo 3.

${ }^{18}$ Drews 1974, 387-93.

${ }^{19}$ Utilizamos a edição de Joan G. Westenholz (Westenholz 1997, 38-49, texto 2), a que a autora chama de Sargon Birth Legend. Esta versão compõe-se de vários documentos neoassírios e um manuscrito neobabilónico (ver páginas 38-39).

${ }^{20}$ A versão em língua suméria desta história fornece uma variante: o seu pai chamar-se-ia La'ibum (Cooper e Heimpel 1983, 76, 1. 11').

${ }^{21}$ Westenholz 1997, 38-41, 1s. 1-11.

${ }^{22}$ Redigida entre o período de Ur III e o período paleo-babilónico. Ver Cooper e Heimpel 1983, 67-82. 
afogando-o num «rio de sangue» ${ }^{23}$. O significado do sonho era óbvio: o favor divino estaria prestes a ser retirado ao rei de Kiš e o dom da realeza concedido ao próprio Sargão: "An e Enlil, com as suas ordens divinas, ordenaram com autoridade que a sua realeza [de Ur-Zababa] fosse alienada, que a prosperidade do seu palácio fosse retirada. $»^{24}$

Como bom servidor do seu soberano, Sargão ter-se-á apressado a relatar o sonho que o afligira a Ur-Zababa. Consciente do significado desta revelação onírica e da ameaça que ela representava para o seu reinado, Ur-Zababa utiliza vários subterfúgios para afastar o seu copeiro. Um deles consistia em fazer com que este cometesse um sacrilégio no exercício das suas funções. Segundo a Crónica do Esagila, redigida já no período neoassírio, Ur-Zababa terá ordenado a Sargão que fizesse uma modificação irregular nas oferendas cúlticas ao templo do deus Marduk, o Esagila. Este, desobedecendo ao seu soberano e recusando-se a cometer o sacrilégio, foi visto com bons olhos por Marduk, que, por esse motivo, lhe dera a «soberania sobre as Quatro Regiões [do mundo]» (LUGAL-ut kibrat arba'i iddin-šu $)^{25}$.

Retomando a versão em Sumério da Lenda de Sargão, o rei de Kiš, além deste subterfúgio, tê-lo-á enviado com uma mensagem até Lugalzagesi, o rei de Uruk. A história deixa implícito que a missiva dirigida ao soberano estrangeiro seria provocatória: Ur-Zababa esperaria que o mensageiro (Sargão) fosse morto pelo teor da mensagem.

Porém, tendo fracassado esta tentativa de Ur-Zababa contra Sargão, este, apercebendo-se da ameaça e da traição do seu próprio soberano, desencadeia uma revolta, da qual sai vitorioso. Por conseguinte, retira o poder ao rei de Kiš e apropria-se do trono, cumprindo a revelação que a deusa lhe havia dado em sonhos.

É a partir desse momento que, como parece ser óbvio, adota o nome pelo qual ficou conhecido: Sargão é a grafia em língua portuguesa do nome Šarrukînu (ou Šarru-kēn), que significa, em Acádico, «rei verdadeiro», ou melhor, «rei legítimo ${ }^{26}$. A ênfase sobre este atributo real contido no nome atesta a necessidade de afirmação da legitimidade de um poder obtido pela força e de modo irregular ${ }^{27}$.

${ }^{23}$ Cooper e Heimpel 1983, 77, 1.14 (fragmento 3N T 296).

${ }^{24}$ Cooper e Heimpel 1983, 76, ls. 8'-9' (frag. TRS 73).

${ }^{25}$ Glassner 2004, 266-67, 1. 58, texto 38. O tema central desta versão tardia é a piedade mostrada pelos soberanos em relação ao templo de Marduk na Babilónia. É óbvio que esta versão refunde certos detalhes, substituindo por exemplo Inanna por Marduk, de modo a dotá-la de um significado mais próximo do seu tempo.

${ }^{26} \mathrm{O}$ nome «Sargão» entra na língua portuguesa, tal como na generalidade das línguas modernas, por influência do Antigo Testamento. Porém, o texto bíblico não se refere ao fundador de Akkad, mas sim a Sargão II, rei assírio do I milénio a.C. (722-705 a.C.), a propósito da conquista de Ashdod (ver Is. 20).

${ }^{27}$ Como referido em CAH 1/2, 419, o nome de «Rei Legítimo» não teria certamente sido dado a Sargão aquando do seu nascimento. 


\section{A LegitimaÇÃo DO PODER.}

A usurpação do poder por parte de Sargão acentua a imagem de «arrivista» que a tradição lhe associou. Neste quadro, o seu percurso até à realeza poderia apenas ser justificada pelo seu mérito pessoal e, ainda mais importante, pela escolha divina. A este propósito, é interessante analisar as suas origens à luz de uma conceção que conheceu grande continuidade na tradição literária e cultural mesopotâmica: a condição do ser "civilizado» como sendo oposta a um estado «bárbaro», aplicado a comunidades não identificadas com o sedentarismo, com a agricultura e a vida urbana. Este elemento foi essencial na construção de uma identidade «civilizada» nas sociedades mesopotâmicas ao longo da sua história ${ }^{28}$. É possível que esteja também presente na Lenda de Sargão, concorrendo justificar o seu poder e explicar a sua ascensão. Um exemplo é o caso da Epopeia de Gilgameš, na qual Enkidu ${ }^{29}$ representa um homem que não pertencia ao mundo civilizado. Criado pelos deuses como a antítese de Gilgameš, o soberano de Uruk, Enkidu nascera «nas montanhas» e não conhecia o pão nem a cerveja, produtos que simbolizavam a vida sedentária e agrícola. Assim, Enkidu, um homem selvagem, comia antes como as feras, suas semelhantes:

«Certamente é Enkidu, nascido nas montanhas (...) pão colocaram diante dele; cerveja colocaram diante dele. Enkidu não comeu o pão, mas olhou desconfiado. Como comer pão, Enkidu não sabia; como beber cerveja, nunca lhe havia sido mostrado.» ${ }^{30}$

A Enkidu é assim atribuída uma natureza próxima dos animais e não completamente humana - leia-se «humano" como "civilizado» ${ }^{31}$. Ao modus vivendi das comunidades nómadas, que desde cedo se estabeleceram na Mesopotâmia, era associado por estas expressões literárias, produzidas em contexto urbano e letrado, este desconhecimento da agricultura. Se a pastorícia era a actividade de subsistência privilegiada pelos nómadas, estes excluíam também, de um modo geral, uma plena vivência da realidade urbana ${ }^{32}$.

${ }^{28}$ Sobre este assunto, consultar Pongratz-Leisten 2001, 195-31.

29 Esta caracterização de Enkidu ocorre sobretudo ao longo das tabuinhas I e II. Consultámos a edição de A. George (George 1999, especialmente 5-11, Tab. 1, e 12-13, Tab. 2).

${ }^{30}$ George 1999, 12-13, Tab. 2. A certas populações, habitando em contextos marginais relativamente ao mundo urbano da Mesopotâmia, eram também associadas estas características «bárbaras». No texto conhecido como A Geografia de Sargão, os homens de Karzina são apresentados como «comedores de carne (...) cujas barrigas não conhecem o pão cozido nem a cerveja» (Horowitz 1998, 75, 1s. 57-59).

${ }^{31}$ Pongratz-Leisten 2001, 202-3.

${ }^{32}$ Segundo A Geografia de Sargão, os Lullubu «não conhecem a construção» (Horowitz 1998, 73, linha 52). 
Habitar em cidades era um critério, que se refletia nos textos literários, que colocava os nómadas numa posição marginal face à civilização. Embora a historiografia tenha, desde há décadas, matizado uma oposição radical entre nomadismo e sedentarismo ${ }^{33}$, certo é que nas cidades se situavam duas referências fundamentais para a definição do ser civilizado: o templo e a realeza. Assim, um texto do período da III dinastia de Ur, conhecido como O Casamento de Martu, traduz claramente o estereótipo associado aos nómadas Martu, ou Amorritas. O nómada «que vive em montanhas, não conhece as moradas dos deuses» é nele descrito como alguém que «habita em tendas, fustigadas pelo vento e pela chuva»; alguém que «durante a sua vida, não tem uma casa» e que, por conseguinte, «quando morrer, não será enterrado».34

A vida «em tendas», segundo estas expressões culturais provenientes de meios urbanos, impedia que o culto aos deuses decorresse de um modo apropriado, pelo facto de ela impedir a existência de templos que lhes servissem de morada e que se constituíssem como referências espaciais e identitárias da comunidade. Impediria também o culto doméstico aos antepassados, pois era entendido como impossível, a quem vivesse em habitações móveis, a tradicional inumação dos mortos debaixo dos pisos das habitações ${ }^{35}$. Entender-se-ia também que a vida fora das cidades implicaria a inexistência da instituição real e da sua expressão física mais visível, o palácio, sem o qual não se conceberia existir a ordem, a intermediação exercida pelo rei entre os planos terreno e divino, ou mesmo a aplicação da justiça ${ }^{36}$.

A Lenda de Sargão, nas suas diferentes versões, poderá conter também um elemento de legitimação do primeiro rei de Akkad, se a perspetivarmos à luz destes parâmetros da cultura mesopotâmica. De facto, segundo estas histórias, Sargão não conhecera o pai nem a mãe e, por essa razão, não possuiria antepassados a quem pudesse prestar o culto doméstico ou sancionar a sua pertença a uma terra ou uma casa. Por outro lado, era também uma espécie de «nómada», pois o berço onde fora depositado pela mãe que o abandonou vogava sem rumo definido, ao sabor do Eufrates.

Todavia, ao ser recolhido por Aqqi, um jardineiro, e ao aprender o seu ofício, Sargão pôde ser introduzido numa das artes mais importantes da civilização, a

33 Rowton 1973, 201-15. Do mesmo modo, a ideia de uma pretensa dicotomia intransponível entre Sumérios e Semitas - como a que opõe nómadas e sedentários -, de uma natureza «racial» dos seus conflitos, ou mesmo a teoria de uma «invasão» semita sobre a Baixa Mesopotâmia, em violenta rutura com a realidade suméria, são vetores de um paradigma há muito abandonado. Consultar Jacobsen 1939, 485-95.

${ }^{34}$ Foi consultada a tradução de Klein 1997, 113-116. Cf. o texto chamado A Geografia de Sargão: dos habitantes de Karzina, o texto afirma que estes «não conhecem o enterramento", isto é, o culto aos mortos (Horowitz 1998, 75, 1. 58).

${ }^{35}$ A inumação dos familiares mortos por baixo dos pisos domésticos, pelo menos entre o período Dinástico Antigo e o período paleo-babilónico, associava-se ao kispum, ou seja, aos rituais e libações aos espíritos das familiares. Consultar Postgate 1992, 98-101.

${ }^{36}$ Pongratz-Leisten 2001, 204. 
agricultura. A recolha da criança à deriva no rio, a sua adoção e posterior acesso a um cargo oficial na corte do rei de Kiš podem ser consideradas como etapas na sua integração plena na sociedade civilizada. Talvez seja pertinente considerar que A Lenda de Sargão, ao incluir estes estereótipos, servia igualmente para explicar o sucesso do fundador de Akkad, um homem que, apesar de nascido entre «bárbaros» e de possuir uma origem que o colocava à margem de uma legitimidade dinástica convencional, teria sido capaz de estabelecer um império sobre parte significativa do Próximo Oriente.

\section{As CONQUistas.}

Após a sua tomada do poder em Kiš, Sargão inicia assim a sua senda de conquistas $^{37}$. A primeira fase da sua expansão seria marcada pelo confronto com Lugalzagesi (ca. 2340-2316). Este, reinando a partir da cidade de Uruk, exerceu uma hegemonia efémera sobre o país de Sumer. O reinado de Lugalzagesi representa um importante precedente para o império de Akkad ${ }^{38}$. Iniciando a sua ascensão como ensi de Umma, conquistara Lagaš, Ur, Larsa e Nippur, obtendo finalmente a realeza sobre a cidade de Uruk. Dominando toda a Baixa Mesopotâmia, Lugalzagesi proclamou-se «Rei do País» (LUGAL KALAM.MA). Porém, assume também um horizonte de poder, concedido pelo deus Enlil, que ultrapassava os estreitos limites da Suméria:

«Quando Enlil, o rei de todos os países [KUR.KUR] concedeu a Lugalzagesi a realeza no país e a justificou aos olhos do país; quando colocou todos os países ao seu serviço e quando, do Levante ao Poente, os submeteu à sua lei.... ${ }^{39}$.

Lugalzagesi, antes da sua derrota às mãos de Sargão, declarava assim exercer o poder «desde o Mar Inferior, pelo Tigre e o Eufrates, ao Mar Superior $»^{40}$. A ascensão da dinastia de Akkad terá adotado como sua esta amplitude política revelada no discurso de poder de Lugalzagesi, concretizando-a e alargando-a. Deste modo se justifica a posição de M. Liverani quando afirma que o império de Akkad, em vez de ser considerado como um "ponto de partida de um processo», deve antes ser entendido como um culminar ou ponto de chegada ${ }^{41}$. As próprias inscrições reais de Sargão, chegadas até nós através das suas cópias paleo-babilónicas, atestam a sua vitória sobre Lugalzagesi:

«Sargão, o rei de Akkad [...], rei de Kiš, ungido de Anum, o rei do País, vigário

\footnotetext{
${ }^{37}$ Ver mapa em anexo, elaborado segundo os dados de M. Liverani (Liverani 1988, 233).

${ }^{38}$ Consultar CAH 1/2, 420-21.

${ }^{39}$ LAPO 3: 94 (IH2b).

${ }^{40}$ Ibid.

${ }^{41}$ Liverani 1993a, 4.
} 
de Enlil, venceu a cidade de Uruk e destruiu a sua muralha. Desafiou Uruk numa batalha e aprisionou Lugalzagesi, o rei de Uruk, no decurso da batalha; levou-o numa coleira até à Porta de Enlil...» ${ }^{42}$

Vencendo aquele que exercia hegemonia sobre a Suméria, Sargão herda também o poder que aquele exercera sobre a Baixa Mesopotâmia. Como o seu antecessor, assume o título de «rei de Kiš», vangloriando-se de ter vencido um total de «trinta e quatro batalhas». Estabelecendo o seu controlo sobre as cidades sumérias, consta que efetuou um gesto simbólico com grande significado, após a conquista de Lagaš, que viria a ser repetido por diversos soberanos assírios do I milénio a.C.: o primeiro rei de Akkad «lavou as suas armas no mar» ${ }^{43}$, afirmando desse modo a sua capacidade de alcançar um dos limites do mundo conhecido, o Golfo Pérsico, e de usufruir do comércio que por essa via entrava na Mesopotâmia.

Com efeito, o domínio do tráfego de produtos através da Mesopotâmia era uma das consequências das conquistas de Sargão. Este declara que, após a sua vitória na Baixa Mesopotâmia, os barcos de Meluhhha, Magan e Tilmun, subindo o Eufrates, já poderiam acostar no «cais de Akkad» ${ }^{44}$. Esta declaração transformar-se-ia num topos recorrente do discurso político e ideológico em séculos posteriores: a capacidade do soberano em fazer canalizar para o centro do seu poder os produtos originários de regiões periféricas, não apenas bens de luxo, mas também matérias-primas escassas na Mesopotâmia, como eram os casos da pedra ou da madeira. No entanto, o controlo do fluxo de mercadorias não se teria limitado ao Golfo Pérsico ou «Mar Inferior»: o acesso a vias de comunicação dirigidas para Norte, ao longo do curso dos rios Tigre e Eufrates, constituíram também um alvo da dinâmica expansionista de Sargão. De facto, este afirma que, com a anuência do deus Dagan, se apropriara do "país superior» e das cidades sírias de Tuttul, Mari, Yarmuti e Ebla, importantes entrepostos no fluxo comercial que atingia, a Norte, a «Floresta dos Cedros» e as «Montanhas da Prata», designações que equivaliam às cadeias montanhosas da Síria do Norte e do Líbano, assim como à cadeia do Tauro, no Sul da Anatólia:

«Sargão, o rei, prosternou-se em Tuttul orando diante de Dagan. Dagan deu-lhe o país superior: Mari, Yarmuti e Ebla, até à Floresta dos Cedros e às Montanhas da Prata».45

Apesar desta afirmação de um alcance de poder que chegava até à Anatólia, devemos talvez ver aqui mais o reflexo de uma capacidade de obtenção de

\footnotetext{
${ }^{42}$ LAPO 3.97 (IIA1a: 1-28).

${ }^{43}$ LAPO 3.97 (IIAla: 29-63).

${ }^{44}$ LAPO 3.99 (IIA1b).

${ }^{45}$ LAPO 3.99 (IIA1b: 17-35).
} 
produtos por via comercial. Contudo, uma epopeia, de que subsistem diversas versões ${ }^{46}$, vulgarmente conhecida como $O$ Rei da Batalha, atribui a Sargão de Akkad uma expedição militar até ao reino de Purušḩhanda ${ }^{47}$. Segundo esta epopeia, da qual seguimos a versão de Amarna (II milénio a.C.), mercadores teriam pedido auxílio a Sargão contra Nur-Daggal, o rei dessa cidade, que os assediava com violência e traições:

«Jurámos lealdade pelo nome de Sargão, rei do Universo, e por isso partimos [para Purušhhhanda]; agora enfrentamos violência e não somos heróis» ${ }^{48}$.

Sargão, ansioso pelo combate e atraído pelas riquezas dessa região - onde existiria uma "grande montanha» feita de lápis-lazúli e ouro -, enceta a demorada e difícil marcha até Purušḩhanda acompanhado pelos seus guerreiros. Vencendo Nur-Daggal, reza a história que o rei de Akkad permanece na região por três anos ${ }^{49}$.

O próprio Sargão não refere nas suas inscrições, que resumem as suas conquistas, qualquer campanha a esta região da Anatólia. Por esse motivo, as opiniões dividem-se quanto à historicidade desta epopeia. Mario Liverani, por exemplo, recusa historicidade a estas informações, atribuindo-lhe o valor de um modelo político e ideológico a ser seguido. Esta perspetiva confere maior relevância ao tempo em que o texto foi redigido e às intenções dos seus autores do que à tentativa de encontrar o que se costuma designar como historical kernel, i.e., um núcleo de informações contidas numa história, lenda, epopeia ou mito, que possa considerar-se ser baseado em acontecimentos históricos concretos $^{50}$.

Por fim, Sargão afirma ter submetido à sua autoridade o Elam ${ }^{51}$, onde reinava a dinastia de Awan. Deve ser notado, porém, que a influência da dinastia de Akkad sobre essa região pode ser atestada historicamente através de um tratado, segundo o qual um rei de Awan se submetia politicamente a Narām-Sîn (ca. 2291-2255 a.C.) um dos mais importantes sucessores de Sargão $0^{52}$.

É bastante difícil, contudo, aferir a real amplitude das conquistas e expedições efetuadas por Sargão. A existência de um texto, chamado A Geografia

\footnotetext{
${ }^{46}$ As diferentes versões, ou recensões, enumeradas por Westenholz 1997, 102.

${ }^{47}$ Este situar-se-ia possivelmente perto da atual cidade de Aksaray (Turquia), numa região já próxima da Anatólia Central. Ver bibliografia em Liverani 1993b, 52, nota 28.

${ }^{48}$ Traduzido a partir de Westenholz 1997, 114, 1. 18.

${ }^{49}$ Westenholz 1997, 131, ls. 27-28.

${ }^{50}$ Liverani 1993b, 52-56. Para algumas referências bibliográficas a favor e contra esta posição, consultar páginas 52-53, nota 29.

${ }^{51}$ LAPO 3.97 (IIAla: 1-34). Acerca da expedição de Sargão ao Elam, consultar Liverani 1988, 234-36.

${ }_{52}$ Publicado pela primeira vez em MDP XI, lxxxviii. Ver também Briend et al. 1992, 8-10.
} 
do Império de Sargão ${ }^{53}$, que enumera as regiões controladas pelo fundador de Akkad, acentua a controvérsia, em vez de esclarecer as dúvidas. Este texto, apenas conhecido por duas tabuinhas ${ }^{54}$, enumera as regiões controladas por Sargão e procura, através da discriminação de distâncias, medir a amplitude do império. Não desejando entrar na discussão das suas fontes ou redação primária $^{55}$, podemos apenas dizer que se trata de um texto de composição complexa, que contém elementos que remetem para realidades pertencentes ao III, II e I milénios a.C., como, por exemplo, os topónimos que enumera ${ }^{56}$. Todavia, é consensual considerar-se este texto como a expressão de um ideal de «império universal» corporizado pela figura de Sargão de Akkad.

A centralidade de Akkad e a sua capacidade de dominar militarmente uma vasta amplitude geográfica reflete-se nas inscrições reais de Sargão, através das quais este afirma manter em permanência uma força bélica que o limitado horizonte das cidades-estado sumérias parecia nunca ter sido capaz de sustentar: o rei de Akkad afirma manter «5400 homens comendo a sua refeição diante dele todos os dias. $\aleph^{57}$ É por essa dinâmica guerreira e por um poder de natureza carismática que Sargão unifica pela primeira vez, toda a Mesopotâmia ${ }^{58}$, fornecendo aos futuros soberanos dessa região uma base ideológica que ajudaria a justificar a reivindicação de um horizonte de poder «universal».

\section{SARGÃo \& SARGÃo.}

Um dos exemplos que ilustram a continuidade da influência que a figura do fundador de Akkad exerceu sobre as conceções da realeza na Mesopotâmia é a adoção do seu nome por alguns reis posteriores ${ }^{59}$. Dois reis assírios escolheram, como seus nomes régios, o nome de Sargão. O mais importante foi Sargão II, monarca cujo papel foi marcante na expansão assíria da segunda metade do I milénio a.C. Este, como o seu homónimo de Akkad, usurpou o trono assírio por volta de 722 a.C., após a morte de Salmanasar V, cujo reinado durou pouco menos de cinco anos (726-722 a.C.). O facto de Sargão II ter chegado ao trono de modo irregular, antes de lhe ser exigido que consolidasse internamente o seu poder pela força, permite entender o motivo pelo qual este adotara o nome do fundador de Akkad: consolidar um poder recém-adquirido e afirmar uma

${ }^{53}$ Transliteração, tradução e estudo em Horowitz 1998, 67-95.

${ }^{54}$ Um manuscrito do período neoassírio, encontrado em Aššur (Ass 13955rb), e um manuscrito neobabilónico, hoje no Museu Britânico (BM 64382): Van de Mieroop 1999. 330.

${ }^{55}$ Ver bibliografia e resumo das posições em Van de Mieroop 1999. 330-31.

${ }^{56}$ Van de Mieroop 1999, 331.

${ }^{57}$ LAPO 3.99 (IIAlb: 17-35).

${ }^{58}$ Liverani 1988, 252-56 acentua o carisma guerreiro dos reis de Akkad como uma das principais inovações da cultura política trazidas por Sargão à Mesopotâmia.

${ }^{59}$ Frahm 2005, 46-50, n. ${ }^{\circ} 2$. 
legitimidade através do nome inequívoco de Šarru-kîn, ou «rei legítimo», como vimos acima ${ }^{60}$.

Sargão II, como o fundador de Akkad, resolveu construir uma nova capital, a que chamou Dūr-Šarrukîn, a «Fortaleza de Sargão», localizada na atual Khorsabad $^{61}$. A fundação de uma nova capital, construída ex nihilo, procurava instituir uma rutura com uma realidade política anterior que proporcionasse um afastamento de contextos de poder tradicional que continham, de forma latente ou aberta, focos de oposição $0^{62}$. Sargão II poderá ter decidido a construção dessa nova cidade como meio de se afastar de uma atmosfera potencialmente conspirativa por parte de elites tradicionais que residiriam, em boa parte, em antigas capitais como Aššur ou Kalhuu, onde teriam grande influência.

Não sendo um expediente político invulgar no Próximo Oriente Antigo, podemos afirmar com certeza que esta seria a mesma estratégia que Sargão pretendera seguir quando fundara a cidade de Akkad. Esta seria o símbolo mais visível de rompimento com a tradicional realidade política da Suméria, que se caracterizava, antes da experiência de Lugalzagesi, na fragmentação em cidades-estado. Esta cidade, que pretendia certamente ser considerada como o «centro» do mundo, que correspondesse às conquistas de Sargão, ainda não foi revelada pelo esforço arqueológico. No entanto, presume-se que estivesse situada numa zona de transição entre a Alta e a Baixa Mesopotâmia, perto de Bagdad $^{63}$.

A Crónica do Esagila ${ }^{64}$, a que já nos referimos, e a chamada Crónica dos Reis Antigos $^{65}$, relatam a fundação de uma nova cidade por Sargão, diante de Akkad, sua capital. Estes textos refletem a atribuição de um significado ao passado de um modo que era comum não apenas na literatura babilónica, mas na própria historiografia produzida no Oriente Antigo em geral: o favor divino e o comportamento dos reis para com os deuses eram fatores determinantes na definição do destino dos homens. No caso concreto destas duas crónicas, os seus autores pretendiam interpretar o percurso histórico de várias dinastias mesopotâmicas segundo o comportamento dos soberanos face ao Esagila, o templo de Marduk na cidade da Babilónia. Este era o critério essencial para explicar a queda

${ }^{60}$ Acerca da importância do nome como veículo da essência das coisas na cultura mesopotâmica e, em especial, relativamente aos nomes dos reis, cf. Van de Mieroop 1999, 329-30 (sobre a homonímia de Sargão de Akkad e Sargão II da Assíria).

${ }^{61}$ Consultar as actas do colóquio dirigido por A. Caubet (1995).

${ }^{62}$ Joffe 1998, 549-80. O autor analisa, entre outros, o caso particular de Dûr-Sharrukîn (Ibid. 562).

${ }^{63}$ Consultar mapa em anexo. Poderia estar mais propriamente entre Sippar e Kiš (Joffe 1998, 556). Ver ainda Wall-Romana 1990.

${ }^{64}$ Glassner 2004, 263-68 (texto 38).

${ }^{65}$ Glassner 2004, 268-71 (texto 39). 
e ascensão de reis e dinastias ${ }^{66}$, incluindo Sargão e outros dos seus sucessores, como Narām-Sîn.

A Crónica dos Reis Antigos segue o fio das tradições literárias acerca de Sargão de Akkad ao relatar como o favor de Marduk recaíra sobre ele, permitindo que este governasse «os países como um só» ${ }^{67}$. Todavia, após aludir às suas conquistas e à amplitude do seu domínio, o texto revela que o rei decide construir uma nova cidade, réplica da cidade de Babilónia, diante da sua capital, Akkad:

«Ele [Sargão] levou terra do "fosso de argila" de Babilónia e construiu, perto de Akkad, uma réplica [da cidade] de Babilónia. Por causa desta (falta) por ele cometida, o grande senhor Marduk, enfurecido, diminuiu o seu povo através da fome. Desde Oriente até ao Ocidente houve uma revolta contra ele, e ele foi afligido com "insónia".»" ${ }^{68}$

Segundo estas crónicas, este ato seria ímpio e sacrílego, pois Sargão, fundando desse modo uma cidade, estaria a competir com a grandeza de Babilónia e, mais do que isso, a substituir-se aos próprios deuses ao encetar esse ato entendido como «demiúrgico». Como afirma M. Van de Mieroop: «The building of a new city by a mortal man was considered to be an act of hybris; to the Mesopotamians only gods were allowed to found cities» ${ }^{69}$.

Este tom negativo foi interpretado por este autor como uma crítica indireta, não ao fundador de Akkad, mas ao próprio Sargão II da Assíria. Esta basear-se-ia no acontecimento inusitado que foi a morte de Sargão II em combate em 705 a.C. e a não recuperação do seu cadáver. Tal facto teria privado o rei dos ritos fúnebres e constituía um sinal, aos olhos de muitos dos seus contemporâneos, de uma punição divina devido a uma falta que este houvesse cometido. Falta o "pecado» que pode estar relacionado com a sua usurpação do poder e a sua tentativa de imunização relativamente a oposições internas, ao construir uma nova cidade de raiz e ao estabelecer nela a capital do império assírio. Por outro lado, não será por acaso que esta memória construída acerca de Sargão de Akkad retome força no momento em que a Assíria empreende um movimento de expansão que a iria tornar, paulatinamente, o precedente para os impérios do I milénio a.C., como o neobabilónico e o persa aqueménida.

Estes dois textos são exemplos pungentes da complexidade das tradições literárias no Próximo Oriente Antigo. Expressam uma utilização inteligente de uma tradição cultural e política antiga, no sentido de estabelecer um critério

${ }^{66}$ Estes textos refletem o anacronismo destes elementos ao associá-los à personagem de Sargão de Akkad. Este facto denuncia o propósito interpretativo desta composição literária à luz do tempo em que foi produzida.

${ }^{67}$ Ver supra nota 24.

${ }^{68}$ Glassner 2004, 271, texto 39.

${ }^{69}$ Van de Mieroop 1999. 338. 
valorativo para as ações dos soberanos, de que Sargão de Akkad constituiria elemento fundamental. Esse critério estabelecia como valor positivo a emulação das conquistas de Sargão. Uma passagem de um texto épico com ele relacionado, inscrito num texto do período paleo-babilónico, revela de modo explícito a natureza modelar do fundador de Akkad. No final do texto, este exorta qualquer soberano que lhe queira seguir os seus passos a imitá-lo: «Sargão instrui as suas tropas: 'Oh, o rei que me quiser igualar - onde eu fui, que ele também vá!'»70

\section{CONSIDERAÇõES FINAIS}

A figura de Sargão de Akkad ultrapassou em muito a sua dimensão histórica concreta. Ao longo de muitos séculos, a memória que sobre ele foi construída transformou-o numa personagem modelar e numa referência política e cultural incontornável. Parte integrante e essencial dessa memória era a tradição que lhe atribuía a conquista das «Quatro Regiões», isto é, do mundo. Esta expressão, apesar de nunca ter feito parte da sua titulatura durante o seu reinado, traduz um horizonte universalista de poder, reclamado por diversas entidades políticas surgidas no Próximo Oriente Antigo. Ainda que a amplitude das suas conquistas possa ter sido exagerada e alargada pela tradição literária, que construiu à sua volta uma verdadeira res gesta, foi Sargão de Akkad, assim como a dinastia que fundou, o responsável, se não pela concretização desse ideal de poder, pelo menos à cristalização da sua ideia.

${ }^{70}$ Sargão, o Herói Conquistador: Westenholz 1997: 76-77, texto 6, 1s. 120-123. 


\section{Bibliografia}

Amiet, Pierre. 1976. L’art d’Agadé au Musée du Louvre. Paris: Éditions des Musées Nationaux.

Brandenstein, C. G., ed. 1934. Kultische Texte in hethithischer und churrischer Sprache (Keilschrifturkunden aus Boghazköi 27). Berlin: Akademie-Verlag.

Edwards, I. E. S., C. J. Gadd e N. G. L. Hammond, eds. (1971) 2006. The Cambridge Ancient History: Early History of the Middle East. Vol. 1, Parte 2. Reimpressão, Cambridge: The Cambridge University Press.

Caubet, A. ed. 1995. Khorsabad, le palais de Sargon II, roi d'Assyrie. Actes du colloque organisé au Musée du Louvre par le Service Culturel le 21 et 22 janvier 1994. Paris: La Documentation Française.

Cooper, J. e W. Heimpel. 1983. “The Sumerian Sargon Legend.” Journal of the American Oriental Society 103:67-82.

Drews, R. 1974. "Sargon, Cyrus and Mesopotamian Folk History." Journal of Near Eastern Studies 3:387-93.

Frahm, E. 2005. "Observations on the Name and Age of Sargon II and Some Patterns on Assyrian Royal Onomastics." N.A.B.U. 2:46-50.

Gadd, C. J. e Leon Legrain, eds. 1928. Ur Excavations Texts: Royal Inscriptions. Vol. 1. London: British Museum / Museum of the University of Pennsylvania.

George, A. 1999. The Epic of Gilgamesh. A New Translation. London: Penguin Books.

Glassner, J.-J. 2004. Mesopotamian Chronicles. Atlanta: Society of Biblical Literature.

Goetz, A. 1947. "Historical Allusions in Old Babylonian Omen Texts." Journal of Cuneiform Studies 1:253-65.

Grayson, A. K., ed. 1987. The Royal Inscriptions of Mesopotamia. Assyrian Periods, vol. 1: Assyrian Rulers of the Third and Second Millennia BC (to 1115 BC). Toronto: University of Toronto Press.

Güterbock, H. 1969. "Ein neues Bruchstück der Sargon-Erzählung, König der Schlacht." Muskellunge der Deutsch Orient-Gesellschaft zoos Berlin 101:14-26.

1934. "Die historische Tradition und ihre literarische Gestaltung bei Babyloniern und Hethitern bis 1200. (Erster Teil: Babylonien)." Zeitschrift für Assyriologie und verwandte Gebiete 42:1-91.

1938. "Die historische Tradition und ihre literarische Gestaltung bei Babyloniern und Hethitern bis 1200 (Zweiter Teil: Hethiter)." Zeitschrift für Assyriologie und verwandte Gebiete 44:45-145. 
'Rei das Quatro Regiões': Sargão de Akkad e o modelo imperial na Mesopotâmia

Horowitz, W. 1998. Mesopotamian Cosmic Geography. Winona Lake: Eisenbrauns.

Jacobsen, Thorkild, 1934. The Sumerian King List (Assyriological Studies 11). Chicago: Oriental Institute of the University of Chicago.

Joffe, A. 1998. "Disembedded capitals in Western Asian Perspective." Comparative Studies in Society and History 40:549-80.

Klein, J. 1997. "The God Martu in Sumerian Literature." In Sumerian Gods and their Representations, ed. L. Finkel e M. Geller, 99-116. Gröningen: Styx.

Liverani, Mario. 1988. Antico Oriente. Storia, Società, Economia. Roma: Laterza.

—_ 1993a. "Akkad: an Introduction." In Akkad: The First World Empire. Structure, Ideology, Traditions, ed. M. Liverani, 1-10. Padova: Sargon, srl.

—_ 1993b. "Model and Actualization. The Kings of Akkad in the Historical Tradition." In Akkad: The First World Empire. Structure, Ideology, Traditions, ed. M. Liverani, 41-67, Padova: Sargon, srl.

Michalowski, Piotr. 1983. "History as Charter: Some Observations on the Sumerian King List." Journal of the American Oriental Society 103:237-48.

Nigro, Lorenzo. 1998. "Two steles of Sargon: iconology and visual propaganda at the beginning of royal Akkadian relief." Iraq 60:85-102.

Oppenheim, A. L. 1964. Ancient Mesopotamia. Portrait of a Dead Civilization. Chicago: The University of Chicago Press.

Pongratz-Leisten, Beate. 2001. "The Other and the Enemy in the Mesopotamian Conception of the World." In Melammu Symposia II: Mythology and Mythologies. Methodological Approaches to Intercultural Influences, ed. R. Whiting, 195-231. Helsinki: The Neo-Assyrian Text Corpus Project.

Postgate, John Nicholas. 1992. Early Mesopotamia. Society and Economy at the Dawn of History. London / New York: Routledge.

Puech, Emile, Jacques Briand e René Labrun. 1992. Traités et Serments dans le Proche-Orient Ancien (Supplement aux Cahiers Évangile 81). Paris: Les Editions du Cerf.

Rowton, M. B. 1960. "The Date of the Sumerian King List." Journal of Near Eastern Studies 19:156-62.

. 1973. "Urban Authonomy in a Nomadic Environment." Journal of Near Eastern Studies 32:201-15.

Scheil, V. 1911. Mémoires de la Délégation en Perse, XI : Textes Élamites-Anzanites, Paris: Ernest Leroux.

Sollberger, E. e J.-R. Kupper, eds. 1971. Inscriptions royales sumériennes et akkadiennes (Littératures Anciennes du Proche-Orient 3). Paris: Centre National de la Recherche Scientifique, Les Éditions du Cerf. 
Speiser, E. 1952. "Some Factors in the Collapse of Akkad." Journal of the American Oriental Society 72:97-101.

Sturm, J.eOtten, H., eds. 1939. Historischeund religiöse Texte (Keilschrifturkunden aus Boghazköi 27); Berlin: Akademie-Verlag.

Van de Mieroop, Marc. 1999. "Literature and Political Discourse in Ancient Mesopotamia: Sargon II of Assyria and Sargon of Agade." In Munuscula Mesopotamica. Festschrift für Johannes Renger (AOAT 267), ed. B. Böck, E. Cancik-Kirschbaum e T. Richter, 327-39. Münster: Ugarit-Verlag.

Wall-Romana, Christophe, 1990. “An Areal Location of Agade." Journal of Near Eastern Studies 49:205-45.

Westenholz, Joan G, 1983. "Heroes of Akkad." Journal of the American Oriental Society 103:327-36. .1997. Legends of the Kings of Akkade: The Texts. Winona Lake: Eisenbrauns. 
